\title{
Implementasi Robot Keseimbangan Beroda Dua Berbasis Mikrokontroler
}

\author{
GRACE BOBBY, ERWIN SUSANTO, FIKY YOSEP SURATMAN \\ Jurusan Teknik Elektro Telkom University Bandung \\ Email : gracebobbysidauruk@yahoo.co.id
}

\begin{abstract}
ABSTRAK
Perkembangan dunia robot berkembang pesat dari tahun ke tahun. Salah satu contohnya ialah Segway Personal Transporter. Variasi teknik dalam pergerakan robot pada lingkungan yang dinamik pun semakin banyak, diantaranya PolePlacement Controller, Fuzzy Logic, Proportional Integrated Derivative Controller (Kontrol PID). Pada penelitian ini Fuzzy Logic akan digunakan sebagai pengontrol robot keseimbangan ini. Pada sistem ini digunakan dua sensor (accelerometer dan gyroscope) untuk mendapatkan pembacaan data yang stabil dan handal. Dari hasil percobaan kalman filter, diperoleh nilai parameter kalman filter yang optimal adalah Qaccelerometer $=0,001$, Qgyroscope $=0,003$ dan Rpengukuran $=0,03$.
\end{abstract}

Kata kunci: Accelerometer, Gyroscope, Fuzzy Logic, Kalman Filter, Selfbalancing Control.

\begin{abstract}
The development of robots is growing rapidly from year to year. One example is the Segway Personal Transporter. A variety of techniques in the movement of the robot in the dynamic environment became more numerous, including PolePlacement Controller, Fuzzy Logic, Proportional Integrated Derivative Controller (PID control). In this project, Fuzzy Logic will be used as an balancing robot controller. In this system, used two sensors (accelerometer and gyroscope) to obtain data readout is stable and reliable. From the experimental of Kalman filter, obtained the optimal parameter values of Kalman filter are Qaccelerometer = 0.001 , Qgyroscope $=0.003$ and Rmeasure $=0.03$.
\end{abstract}

Keywords: Accelerometer, Gyroscope, Fuzzy Logic, Kalman Filter, Self-balancing Control. 


\section{PENDAhUlUAN}

Di dunia modern saat ini. Penelitian mengenai robot sangatlah banyak dan berkembang pesat, disertai dengan kemajuan teknologi yang terus menerus berkembang. Salah satu yang membuat penulis ingin untuk mengembangkan pengetahuannya mengenai robot dan sejenisnya. Robot yang akan dibahas disini adalah robot yang akan dapat menyeimbangkan dirinya hanya dengan dua roda. Dimana pada saat ini kita sudah mengenal adanya kendaraan Segway Personal Transporter. Kendaraan yang memiliki dua roda, dikanan dan dikiri sebagai penyeimbangnya.

Di sini akan dirancang prototip dari Segway. Seperti yang sudah dibahas sebelumnya, ini juga merupakan pengembangan dari pendulum terbalik yang di letakan diatas kereta beroda. Sedangkan tujuan dari penilitian ini ialah mendesain suatu sistem kontrol yang handal agar robot dapat berdiri tegak.

Untuk dapat menyeimbangkannya dibutuhkan metode kontrol yang baik dan handal untuk mempertahankan posisi robot dalam keadaan tegak lurus terhadap permukaan bumi tanpa memerlukan pengendali dari luar dan menerapkan Self-balancing Control. Maka dari itu penulis memilih kontrol Fuzzy Logic sebagai kontrol yang dapat menciptakan kontrol sesuai dengan yang diharapkan penulis. Penentuan pada metode control Fuzzy Logic ini ialah dikarenakan dengan menggunakan Fuzzy Logic ini keluaran dari system berupa crisp tegas yang dapat menjaga kestabilan robot yang dibuat.

Pada penelitian ini digunakan Arduino uno, serta memakai sensor accelerometer dan gyroscope yang akan mengendalikan motor DC. Masalah yang didapatkan pada penelitian ini antara lain ialah merealisasikan kontrol Fuzzy Logic pada sistem robot dengan merealisasikan Kalman Filter agar pembacaan sensor akurat. Sehingga robot ini dapat mempertahankan posisinya tegak lurus dengan seimbang terhadap permukaan bumi pada bidang datar. Dan dapat menerapkan Self-balancing Control pada robot.

\section{Balancing Robot}

Balancing robot beroda dua merupakan suatu robot mobile yang memiliki dua roda di kedua sisinya dan tidak akan seimbang tanpa sebuah metode kontrol yang baik(Wibowo, 2013). Saat balancing robot beroda dua cenderung ke depan atau miring ke kanan pada Gambar 1, maka yang perlu dilakukan adalah motor akan memutar searah jarum jam sehingga balancing robot beroda dua akan berputar ke arah depan. Gaya yang digunakan untuk menyeimbangkan dihasilkan dari putaran roda. 


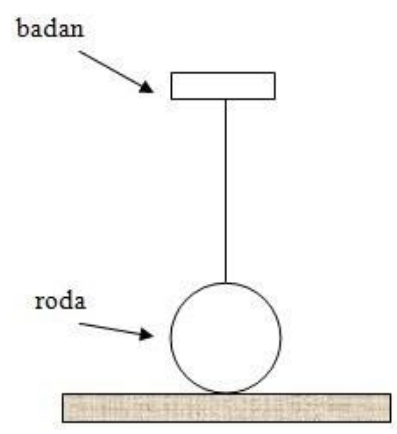

(a)

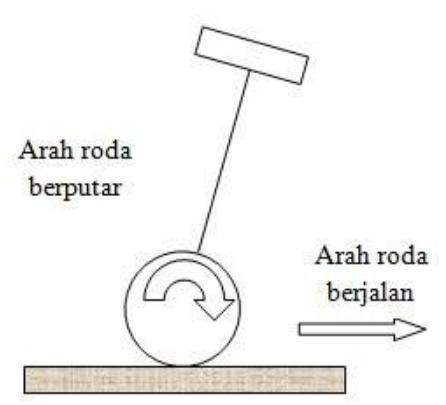

(b)

\section{Gambar 1. Balancing Robot Beroda Dua Menyeimbangkan Diri.}

(a) Posisi Robot Seimbang

(b) Arah Roda Berjalan dan Berputar Ketika Posisi Miring ke depan.

\section{Logika Fuzzy}

Logika Fuzzy merupakan logika dalam pengambilan keputusan yang digunakan untuk memecahkan masalah dengan sistem yang sulit untuk dimodelkan, teori tentang fuzzy set pertama kali diperkenalkan dan dikembangkan oleh Dr. Lotfi A. Zadeh dari Universitas California, Berkeley pada tahun 1965. Dalam kehidupan banyak masalah dengan informasi yang sulit direpresentasikan ke dalam sebuah model rumus atau angka yang pasti karena informasi tersebut bersifat kualitatif (tidak bisa dihitung secara kuantitatif).

\section{Driver Motor}

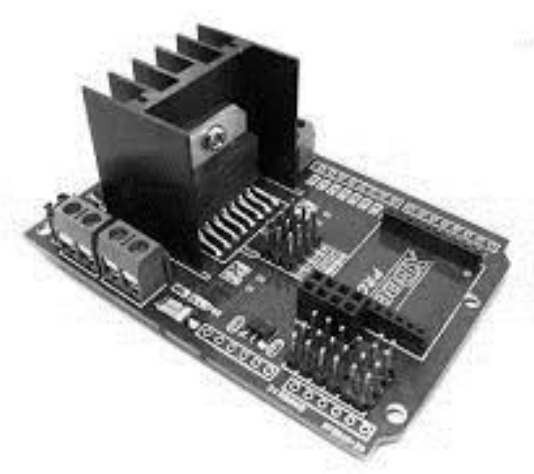

\section{Gambar 2. Driver Motor DC}

Antara mikrokontroler dengan suatu motor. Fungsi driver motor yaitu untuk menjalankan motor sebagai mengatur arah putaran motor maupun kecepatan putaran motor dan digunakan driver motor karena arus yang keluar dari mikrokontroler tidak mampu memenuhi 
kebutuhan motor DC, serta mengubah tegangan yang dikeluarkan mikrokontroler agar sesuai dengan tegangan yang dibutuhkan motor tersebut.

Pada penelitian ini digunakan satu jenis driver motor, yaitu driver motor MotoMama Itead Studio yang ditunjukkan pada Gambar 2. MotoMama merupakan basis driver motor perisai H-Bridge di ST L298N Chip.

\section{Sensor Kemiringan}

Dalam dunia elektro mekanik ada beberapa alat sensor gerak yang dapat digunakan dan salah satunya adalah accelerometer dan gyroscope. Secara sederhana accelerometer merupakan sebuah alat untuk sensor posisi dan perpindahan sedangkan gyroscope digunakan sebagai sensor sudut/gerak rotasi. Baik accelerometer maupun gyroscope sudah banyak diterapkan terutama pada bidang mekanika khususnya sistem keseimbangan.

\section{Inertial Measurement Unit (IMU)}

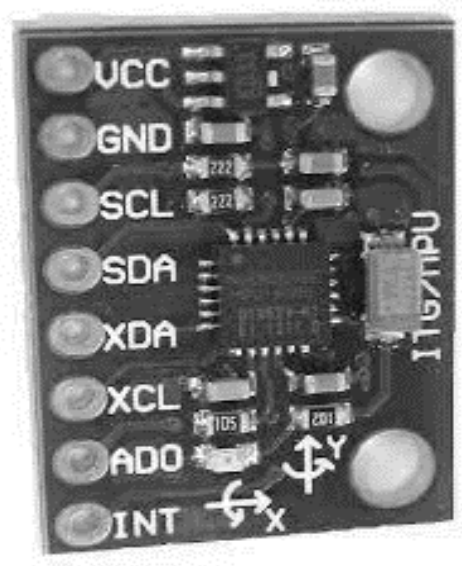

\section{Gambar 3. IMU 6050}

Gambar 3 ialah sensor MPU-6050. IMU digital ini memiliki 3-axis accelerometer dan 3-axis gyroscope yang mana sensor ini terhubung secara I2C, dan ketika dikombinasikan dengan filter, akan menampilkan pembacaan kemiringan yang sangat stabil.

\section{Motor DC}

Agar robot dapat berdiri tegak dengan stabil maka pemilihan motor DC sangatlah penting. Motor DC dengan torsi dan RPM yang tinggi menjadi sangat krusial untuk kestabilan robot. Sementara yang penulis pakai ada motor DC N20 motor yang ditunjukkan pada Gambar 4. 


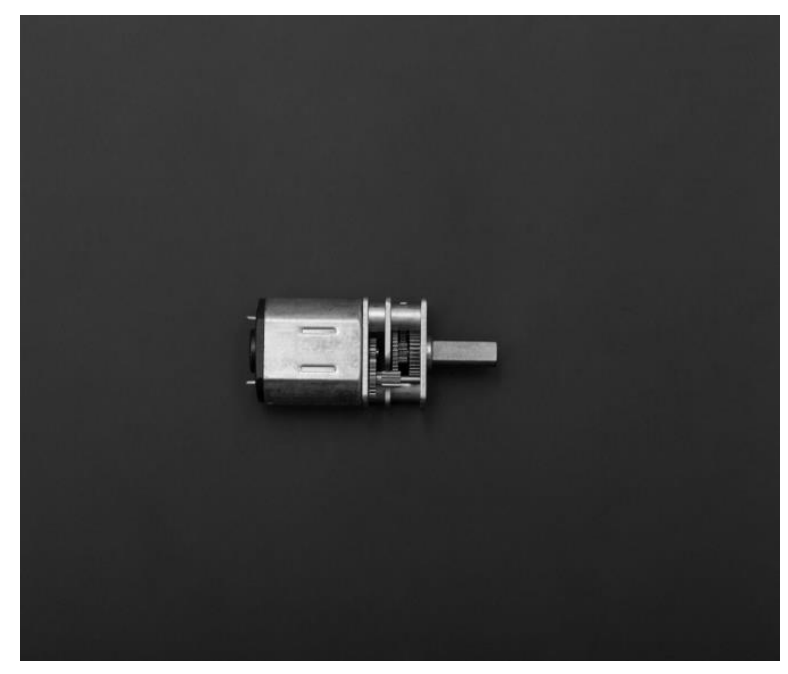

Gambar 4. Motor DC

\section{Arduino Uno}
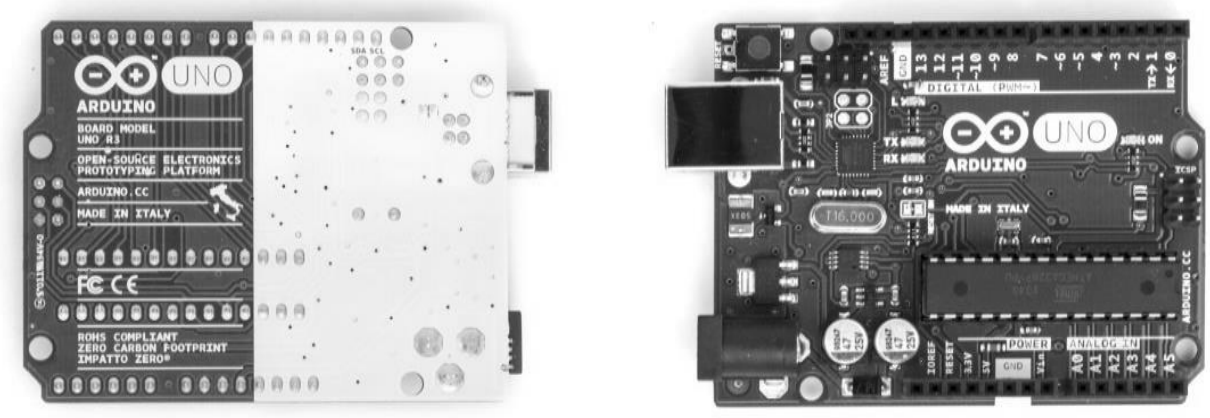

\section{Gambar 5. Arduino Uno}

Arduino Uno merupakan sebuah perangkat mikrokontroler berbasis ATMega 328. Seperti halnya mikrokontroler lain, Arduino Uno juga memiliki fasilitas dasar dari mikrokontroler. Arduino Uno memiliki 14 pin input/output digital, dengan 6 diantaranya bisa digunakan sebagai PWM (Pulse With Modulation), 6 pin input analog, ICSP header, $16 \mathrm{MHz}$ kristal osilator, USB port dan tombol reset yang ditunjukkan pada Gambar 5.

\section{Kalman Filter}

Penulis ingin menunjukan kelebihan Kalman filter untuk memberi prediksi yang baik untuk sudut robot terhadap permukaan bumi dan menjaga robot agar tetap seimbang. Karena Kalman Filter digunakan untuk menghilangkan segala noise pengukuran pada accelerometer dan gyroscope. Kelemahan dari Filter ini sendiri adalah tidak adanya standar dalam metode 
mendapatkan persamaan matematis yang akan digunakan di Kalman Filter. Inilah yang membuat Kalman Filter menjadi kompleks. Kelemahan pada implementasi Kalman Filter pada sistem embedded adalah besarnya beban yang diberikan pada mikrokontroler. Dikarenakan pada akan mengerjakan perhitungan matriks yang kompleks.

\section{PERANCANGAN SISTEM}

Perancangan robot keseimbangan terdiri dari blok sistem yang diintegrasikan menjadi satu sistem utuh. Pembagian blok sistem dibagi menjadi blok sensor, blok pengolahan data, dan blok keluaran (Pamungkas,A.P, 2013). Pada blok sensor, robot menggunakan sensor IMU sebagai masukan. Pertama adalah gabungan sensor accelerometer dan gyroscope yang berfungsi untuk mengukur derajat robot yang berporos pada pusat bumi. Pada bagian keluaran merupakan pengaturan arah pergerakan dan kecepatan dua motor DC yang dipasang secara diferensial dengan menggunakan driver motor. Data yang dihasilkan dari bagian pengolahan akan digunakan untuk mengatur arah gerak dari kedua motor serta mengatur kecepatannya menggunakan duty cycle. Berikut ini adalah diagram blok dari sistem yang digunakan dalam penelitian ini:

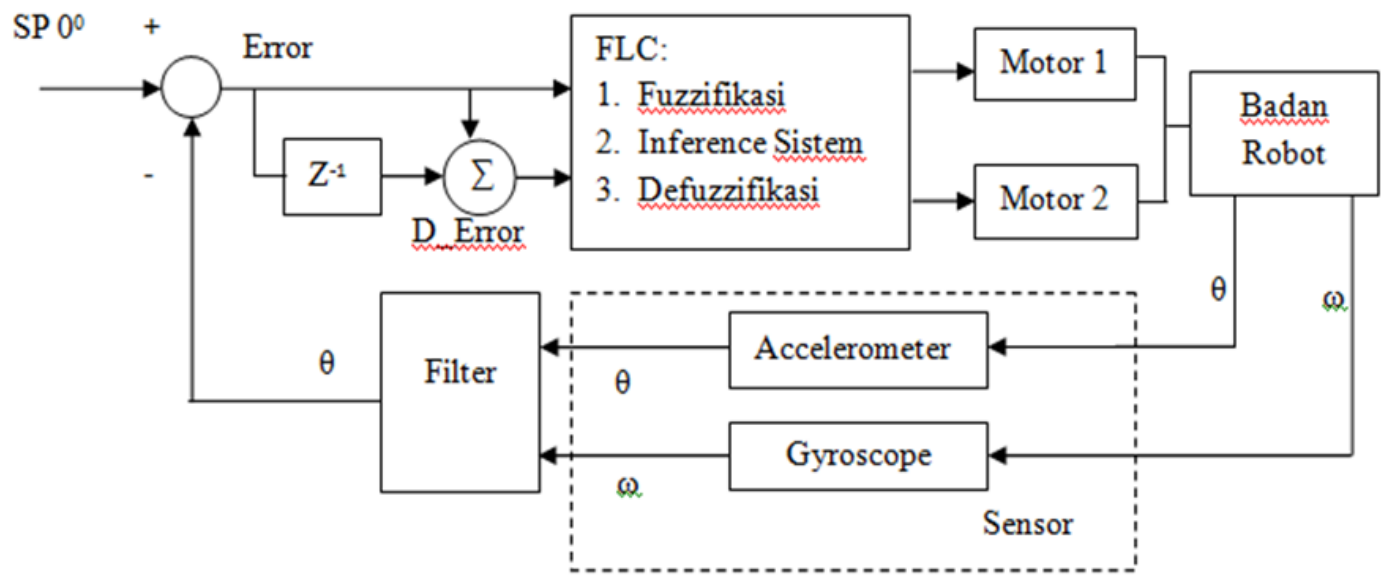

Gambar 6. Diagram Blok Sistem

Gambar 6 adalah struktur kerja system. Nilai masukan (Set Point) sistem berupa nilai derajat yang dikehendaki ialah $0^{\circ}$. Hasil dari keluaran kendali berupa tegangan dalam bentuk PWM (Pulse Width Modulation). Sensor accelerometer dan gyroscope akan bekerja untuk mengukur nilai dari derajat robot (Present Value) dan kemudian menjadikan nilai pembacaan sebagi nilai umpan balik negatif.

Pada Gambar 7 akan menjelaskan alur kerja dari perangkat yang digunakan pada penelitian ini. 


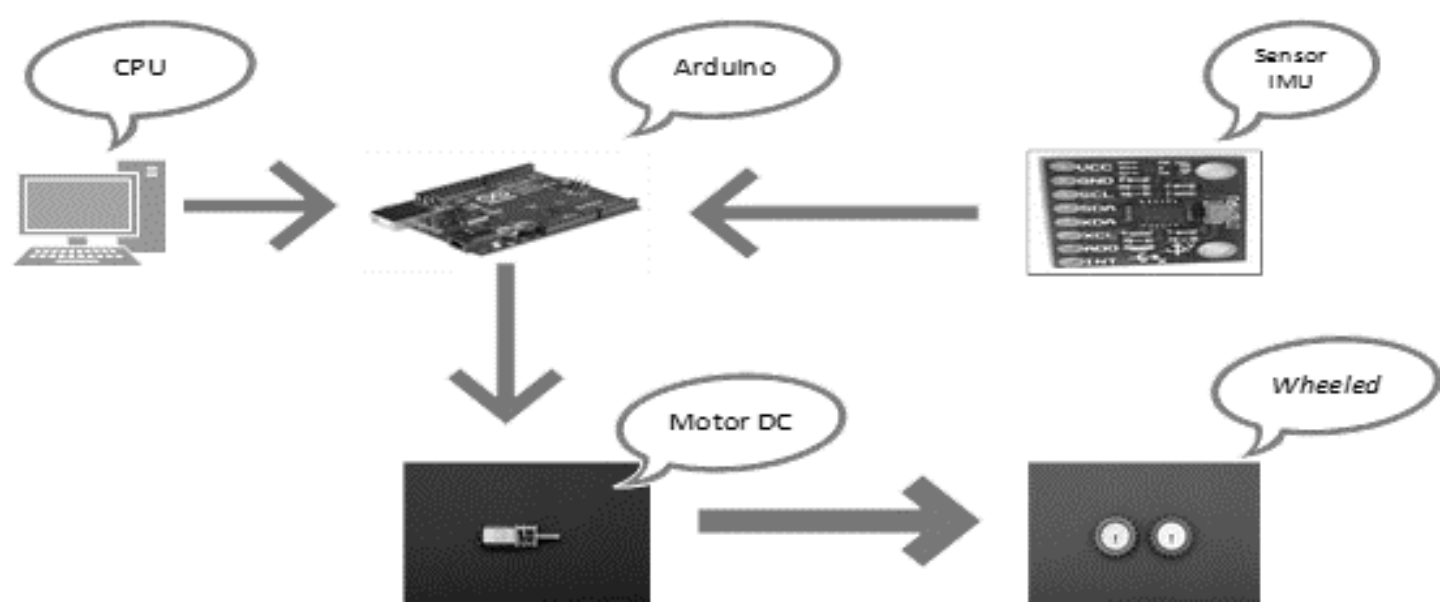

Gambar 7. Alur Kerja Perangkat

Gambar 7 menunjukan alur proses kerja keseluruhan perangkat. Proses pemrograman digunakan melalui Arduino Uno R3 yang terhubung secara serial terhadap PC (Personal Computer). Dalam program Arduino telah diatur nilai set point dari sistem sebesar $0^{\circ}$. Mikrokontroler kemudian menghasilkan nilai PWM untuk menyeimbangkan robot. Nilai derajat dari badan robot kemudian akan dibaca kembali oleh sensor IMU secara analog. Untuk proses analisis data, digunakan perangkat lunak, untuk plotting data yang dibaca secara serial di Arduino.

Sementara untuk flowchart sistem yang digunakan oleh mikrokontroler dapat dilihat pada Gambar 8 berikut ini : 

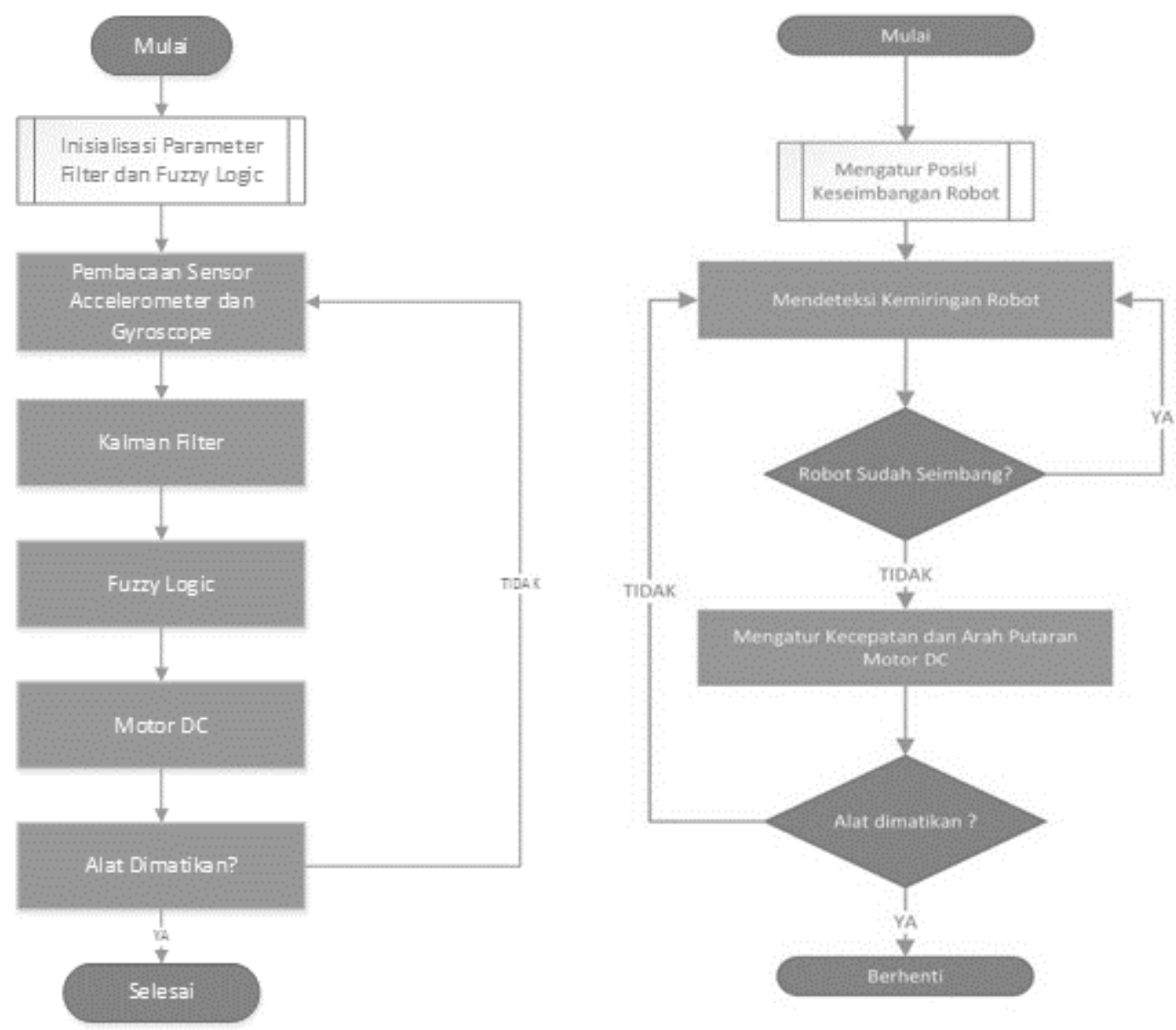

Gambar 8. Flowchart sistem kerja dan perancangan hardware

Flowchart pada Gambar 8 merupakan urutan kerja sistem robot keseimbangan yang dibuat. Yang pertama dilakukan adalah menentukan keseimbangan dari robot. Selanjutnya dari yang sudah dirancang maka dengan otomatis program akan memilih kecepatan dan arah putar motor DC.

Flowchart pada Gambar 8 yang kedua menunjukan urutan kerja dari perangkat lunak yang dirancang. Yang pertama dilakukan adalah inisialisasi parameter Fuzzy Logic dan kalman filter. Lalu setelah mendapat nilai pembacaan dari sensor akan dibaca menggunakan metode kalman filter untuk mendapat kemiringan robot yang mana nilai tersebut akan di proses dalam Fuzzy Logic dan mengeluarkan output berupa PWM untuk menggerakkan motor dengan kecepatan dan arah putaran yang sudah ditentukan. 


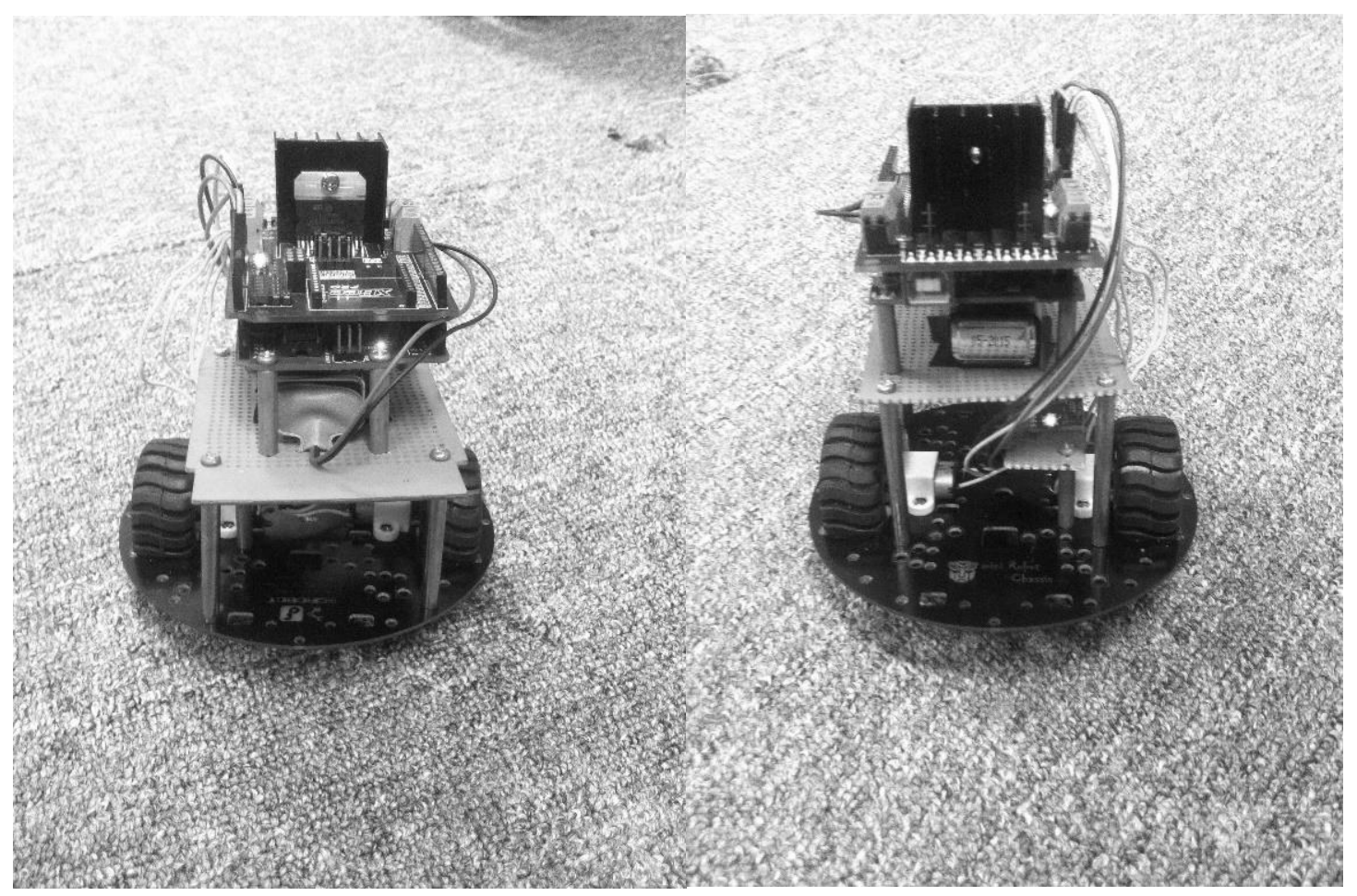

Gambar 9. Bentuk Fisik Robot tampak Depan dan Belakang

Gambar 9 menunjukan robot tampak depan dan belakang. Bentuk fisik robot ini mempunyai tinggi $132 \mathrm{~mm}$ dan Chassis diameter $122 \mathrm{~mm}$. Ruang antara plat memberikan keluasaan untuk meletakan komponen elektrik dan hardware lainnya. Jarak antara Chassis dan tanah $15 \mathrm{~mm}$ diameter roda $42 \times 19 \mathrm{~mm}$. Dua buah motor DC ditempelkan di plat yang paling bawah.

\subsection{Perancangan Fuzzy Logic}

Logika fuzzy digunakan sebagai pengolah data masukan dari sensor IMU. Hal ini bertujuan agar proses penyeimbangan berjalan lancar.

\subsubsection{Fuzzyfication}

Data hasil pembacaan sensor IMU merupakan data masukan bernilai tegas (crisp) kemudian diubah menjadi himpunan fuzzy menurut fungsi keanggotaannya (Priyoprahastyo, 2015).

Proses awal dari fuzzyfikasi adalah membuat membership function (fungsi keanggotaan) dari masukan, serta menentukan banyaknya variable linguistic dalam fungsi keanggotaan tersebut. Dari fungsi keanggotaan yang dibuat akan diketahui nilai derajat keanggotaan dari masing-masing variable dalam himpunan fuzzy berdasarkan masukan tegas (crisp).

Pada sistem ini terdapat masukan dari sensor IMU. Masukan dari sensor IMU ini memiliki masing-masing empat nilai linguistik untuk masing-masing sensor NE, AZE1, AZE2 dan PE. 
Masukan kedua dari delta error NDE, AZDE1, AZDE2 dan PDE dengan fungsi keanggotaan bahu trapesium.

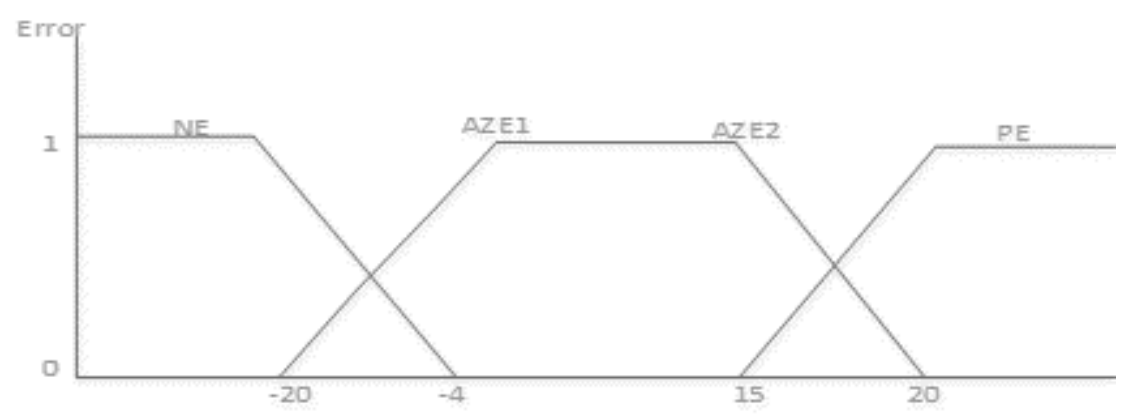

Gambar 10. Fungsi keanggotaan masukan sensor error

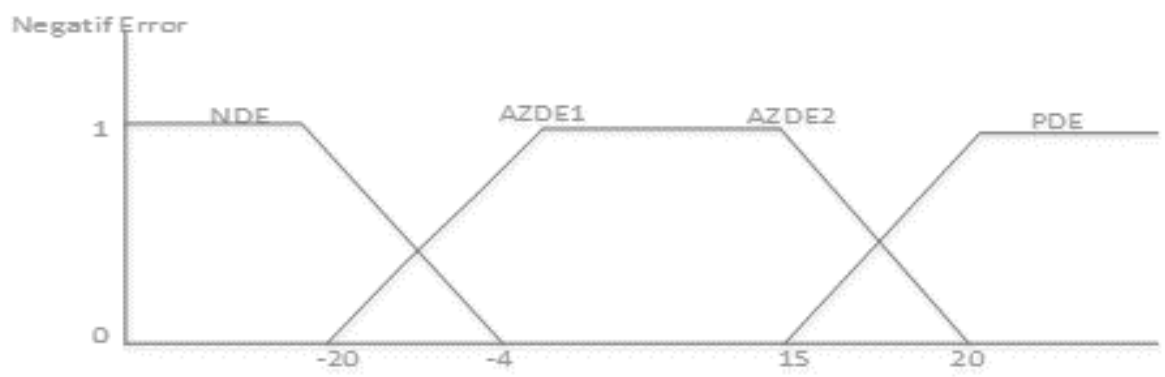

Gambar 11. Fungsi keanggotaan masukan sensor negatif error

Pada keluaran sistem menggunakan model sugeno, pembentukan fungsi keluaran pada model sugeno memiliki fungsi yang lebih sederhana dengan respon lebih cepat dari model yang lain. Bentuk keluaran fungsi keanggotaan pada model sugeno mempunyai bentuk singletone, bentuk dengan derajat keanggotaan satu pada suatu nilai crisp tunggal dan nilai nol pada suatu crisp yang lain.

Karena keluaran dalam bentuk singletone maka fungsi pada setiap nilai linguistik bernilai satu dan nol pada diluar nilai linguistik. Keluaran pada sistem yang dibuat ada dua, yaitu PWM pengontrol motor dc kanan dan kiri. Untuk keluaran sistem yang berupa kecepatan memiliki lima nilai linguistik, yaitu: MUNDUR CEPAT, MUNDUR, BERHENTI, MAJU, MAJU CEPAT. 


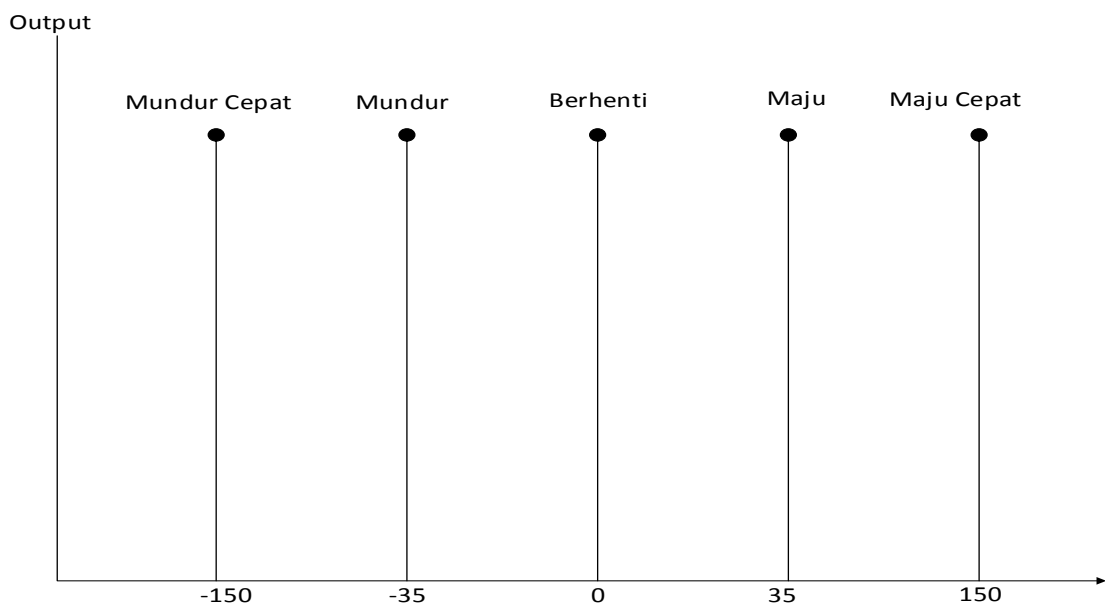

Gambar 12. Fungsi keanggotaan keluaran motor

\subsubsection{Rule Inference}

Pada rule inference, terjadi proses pengolahan data masukan fuzzyfikasi dengan hasil keluaran yang dikehendaki dengan aturan-aturan tertentu. Dari aturan-aturan yang dibentuk inilah yang nantinya akan menentukan respon dari sistem terhadap berbagai kondisi set point dan gangguan yang terjadi pada sistem yang akan dibuat. Rule inference sistem tertulis pada Tabel 1.

Tabel 1. Rule Inference motor

\begin{tabular}{|c|c|c|c|c|}
\hline $\begin{array}{c}\text { Delta } \\
\text { Errpr }\end{array}$ & NE & AZE1 & AZE2 & PE \\
\hline NDE & MC- & MC- & M+ & M+ \\
\hline AZDE1 & M- & M- & B & M+ \\
\hline AZDE2 & MC- & M- & B & MC+ \\
\hline PDE & M- & B & MC + & MC+ \\
\hline
\end{tabular}

Keterangan : MC-=Mundur Cepat, $\mathrm{M}-=$ Mundur, $\mathrm{B}=$ Berhenti, $\mathrm{M}+=$ Maju, $\mathrm{MC}+=$ Maju Cepat. . Berdasarkan tabel, maka sistem mempunyai 16 aturan fuzzy, yaitu:

1 Jika Error $=$ NE dan Delta Error $=$ NDE maka Motor DC $=$ MUNDUR CEPAT.

2 Jika Error $=$ NE dan Delta Error $=$ AZDE1 maka Motor DC $=$ MUNDUR.

3 Jika Error $=$ NE dan Delta Error $=$ AZDE2 maka Motor DC $=$ MUNDUR CEPAT.

Sampai dengan

16 Jika Error $=$ PE dan Delta Error $=$ PDE maka Motor DC $=$ MAJU CEPAT. 


\subsubsection{Defuzzyfication}

Deffuzifikasi merupakan pemetaan bagi nilai-nilai fuzzy keluaran yang dihasilkan pada tahap rules inference ke nilai-nilai keluaran kuantitatif. Pada perancangan robot mobil ini proses deffuzifikasi menggunakan metode Weigth Average dan keluaran dari proses deffuzifikasi berupa nilai PWM yang nantinya digunakan untuk mengontrol kecepatan motor DC.

\subsection{Kalman Filter Diskrit}

Kalman filter merupakan filter digital rekursif yang dapat mengestimasi proses dengan sangat efektif. Kalman filter dapat mengurangi noise pada pengukuran sensor sebelum masuk ke dalam sistem kontrol. Oleh karena itu kalman filter sering digunakan pada sistem kontrol yang sensitif terhadap noise karena dapat meminimalkan square error. Pada implementasinya kalman filter tidak memerlukan data yang harus disimpan. Setiap data pengukuran yang masuk akan diproses ulang. Sehingga kalman filter akan lebih mudah untuk diimplementasikan pada mikrokontroler(Royyan,2015). Sebelum kalman filter digunakan untuk membaca data dari sensor, proses atau sistem harus dimodelkan dalam sistem linear.

$$
\begin{array}{r}
x_{k}=A x_{k-1}+B u_{k}+w_{k-1} \\
z_{k}=H x_{k}+v_{k}
\end{array}
$$

Persamaan 1 merepresentasikan persamaan state proses. $x_{k}$ merupakan kombinasi dari nilai sebelumnya dengan sinyal $u_{k}$ dan process noise. $A, B$, dan $H$ menyatakan state matrices, $w_{k-1}$ menyatakan process noise. Persamaan 2 merepresentasikan persamaan output state. $z_{k}$ adalah nilai yang terukur dari sensor, dan $v_{k}$ menyatakan noise pengukuran. Noise proses $w_{k-1}$ dan noise pengukuran $v_{k}$ tidak memiliki hubungan karena keduanya merupakan independent random noise variables. Tapi keduanya dapat dimisalkan dengan matrik kovarian $Q_{w}$ dan $R_{v}$. Sehingga dapat dituliskan pada Persamaan 3 dan 4.

$$
\begin{aligned}
Q_{w} & =E\left[w_{k} w_{k}^{T}\right] \\
R_{v} & =E\left[v_{k} v_{k}^{T}\right]
\end{aligned}
$$

Dari Persamaan 3 dan 4, T adalah matrix transpose dan $E$ merupakan nilai estimasinya. Process noise covariance $\left(Q_{w}\right)$ matrix dan measurement noise covariance $\left(R_{v}\right)$ merupakan komponen penting dalam kualitas hasil dari keluaran kalman filter. Kedua matriks kovarian ini dapat diperoleh dengan menggunakan persamaan statistic. Namun, pada penelitian ini penulis menggunakan metode tunning. Yaitu dengan trial and error sampai mendapat nilai yang paling baik untuk pembacaan sensor yang digunakan. Kalman filter memperkirakan keluaran sensor dengan skema umpan balik. Pertama, kalman filter akan memperkirakan keadaan pada suatu waktu. Lalu mengambil nilai pengukuran yang ber-noise dalam bentuk umpan balik. Maka perhitungan dari kalman filter akan terbagi menjadi dua bagian, yaitu Time Update (kondisi prediksi) dan Measurement Update (kondisi koreksi). Dua persamaan inilah yang menjadi dasar dari kalman filter. 


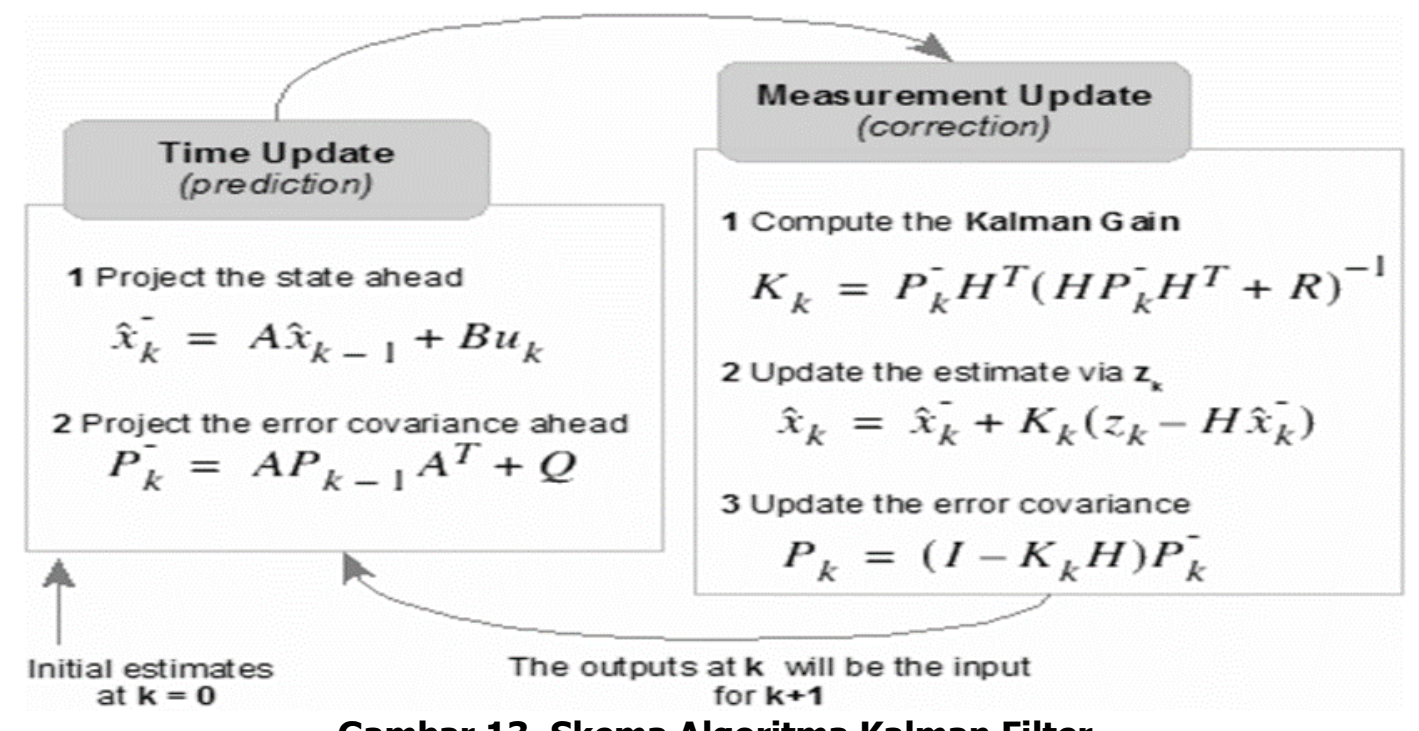

Gambar 13. Skema Algoritma Kalman Filter

\section{PENGUJIAN}

Pengujian pada penelitian ini terbagi menjadi 3 bagian dan bertahap :

1. Pengujian Kalman Filter

2. Pengujian Fuzzy Logic

3. Kesimpulan atau nilai keseluruhan kinerja Robot

\subsection{Pengujian Kalman Filter}

Seperti yang sudah dijelaskan, tujuan utama dari Kalman filter adalah menghilangkan noise pengukuran pada sensor accelerometer serta mengurangi drift dari gyroscope (Putra,2015). Kalman filter memberikan prediksi sudut yang lebih baik dari data asli dari accelerometer. Agar filter dapat berjalan dengan lancar, maka perlu dilakukan tuning manual (Boskovich,1993). Parameter yang perlu dituning adalah Qw dan Rv. Matriks Qw terdiri dari noise proses,yaitu Q_angle dan Q_bias sedangkan Rv merupakan noise pengukuran yaitu R_measure. 


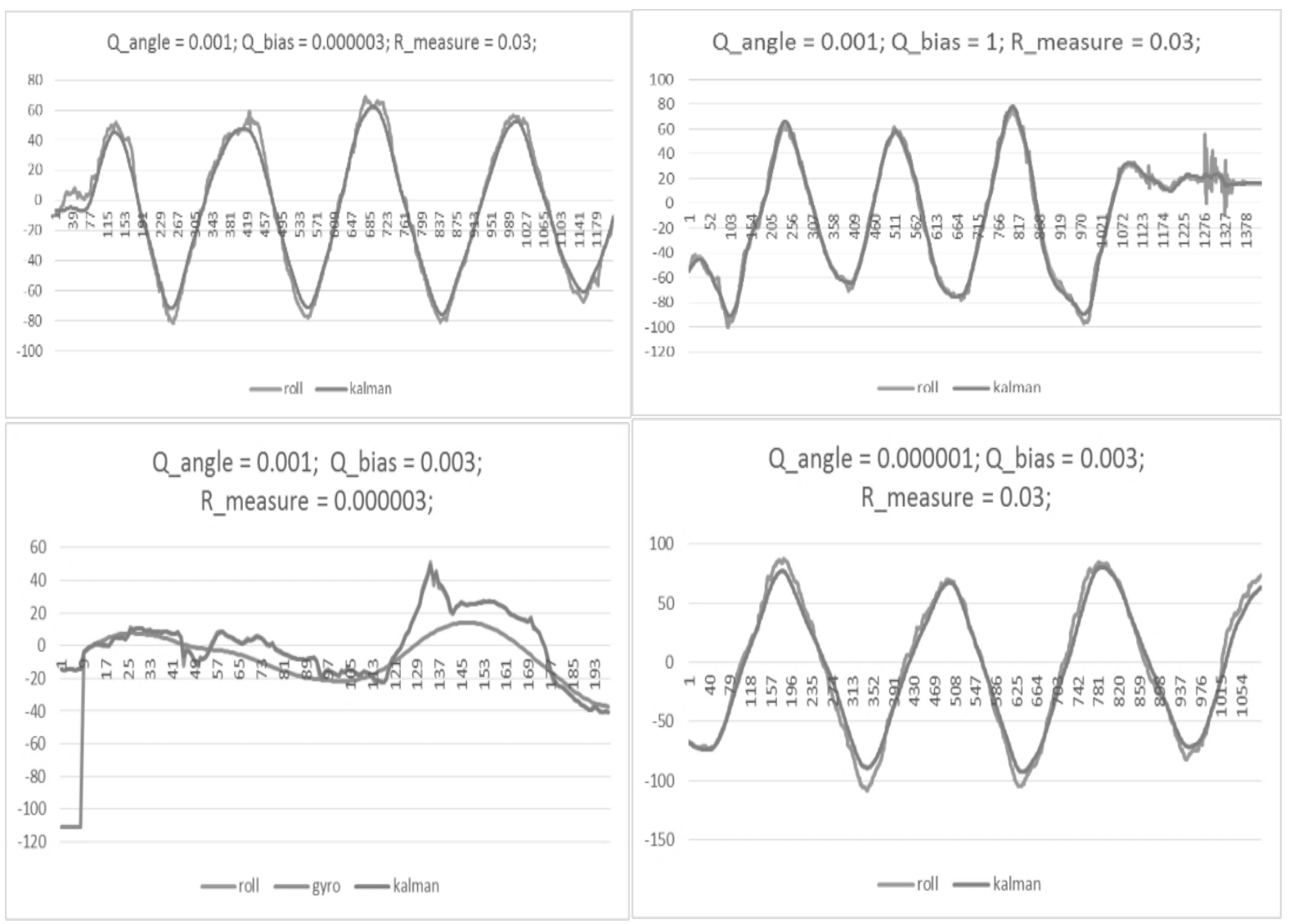

Gambar 14. Tuning yang tidak baik

Dari Gambar 14 kita dapat melihat bahwa keluaran dari kalman filter (bewarna kuning) masih mendominasi pemilihan pembacaan sensor yaitu pembacaan dari accelerometer ataupun gyroscope. Sedangkan yang diharapkan pada penelitian ini kalman filter dapat menggabungkan kedua sensor tersebut dan mengurangi noise yang dimiliki masing-masing sensor atau memprediksi sudut keluaran yang sesungguhnya. 


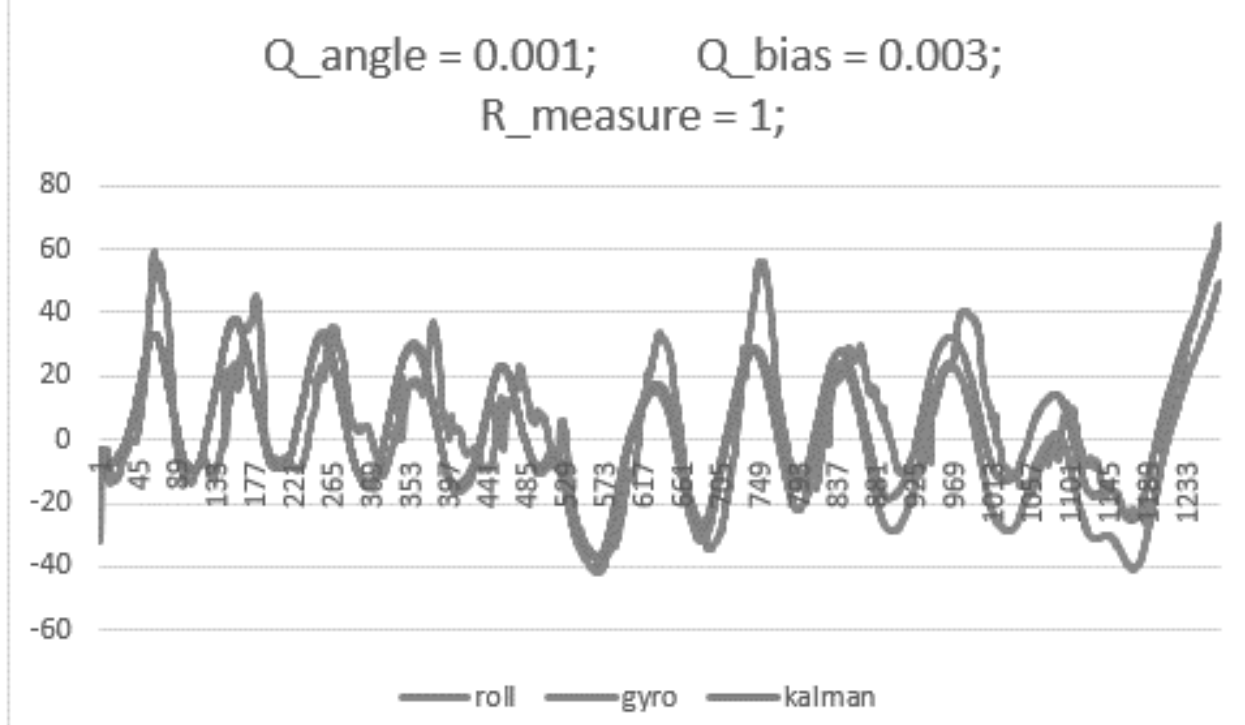

Gambar 15. Tuning R_measure

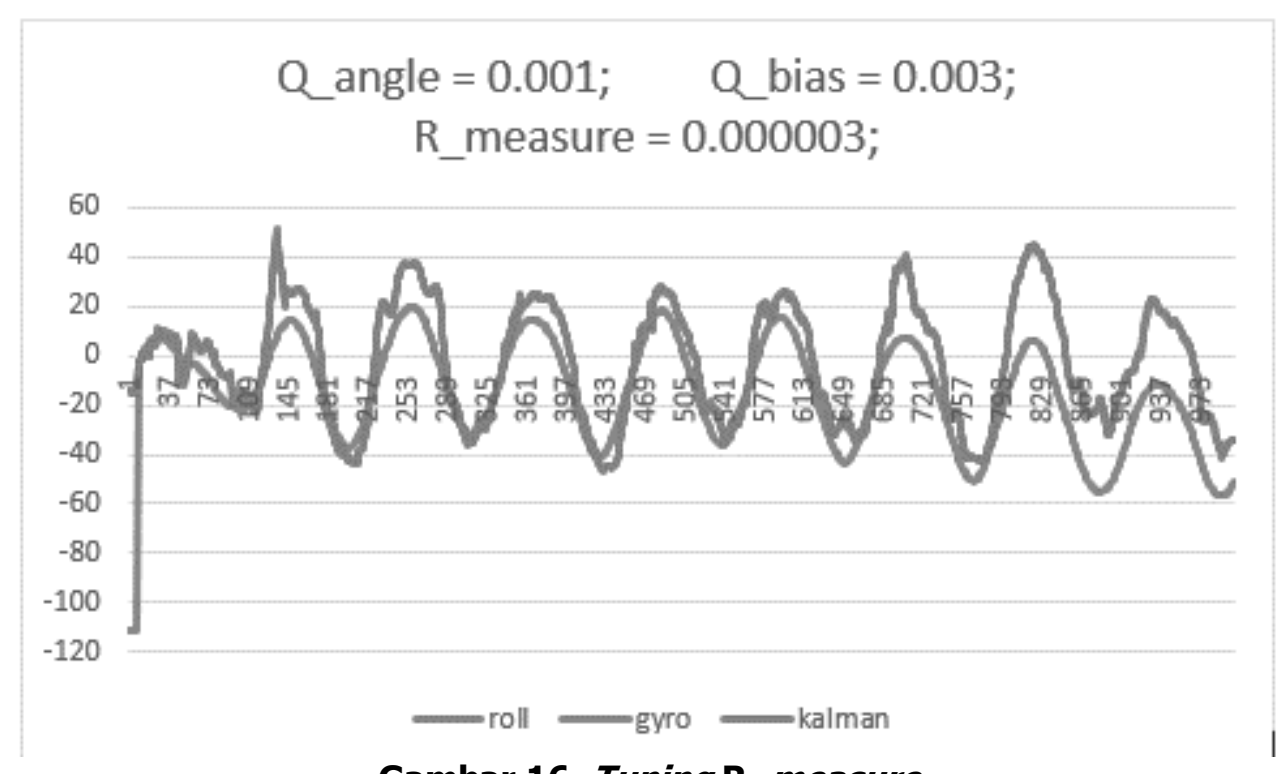

Gambar 16. Tuning R_measure

Dari Gambar 15 dan Gambar 16 diatas diperoleh bahwa perubahan nilai R_measure menjadi lebih besar membuat membuat terjadinya overshoot pada awal pembacaan. Diawal Terlihat bahwa kalman mengikuti sudut pembacaan dari accelerometer tapi seiring jalan kalman pun mengikuti nilai pembacaan dari gyroscope atau mengikuti nilai bias yang tidak respon terhadap waktu yang sebenarnya. Disinilah kita harus menemukan atau menentukan parameter yang tepat untuk R_measure. 
Implementasi Robot Keseimbangan Beroda Dua Berbasis Mikrokontroler

$$
\begin{gathered}
\mathrm{Q} \text { angle }=0.000001 ; \mathrm{Q} \text { bias }=0.003 ; \\
\qquad \_ \text {measure }=0.03 ;
\end{gathered}
$$

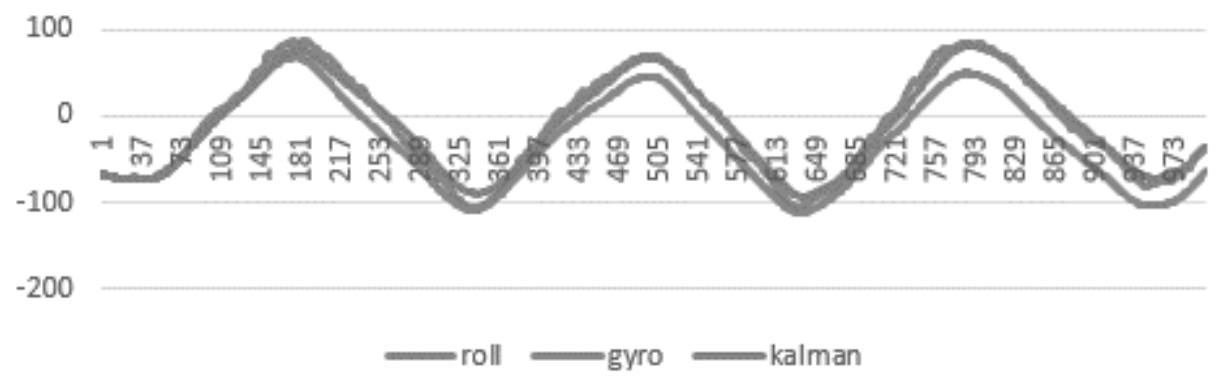

\section{Gambar 17. Tuning Q_w}

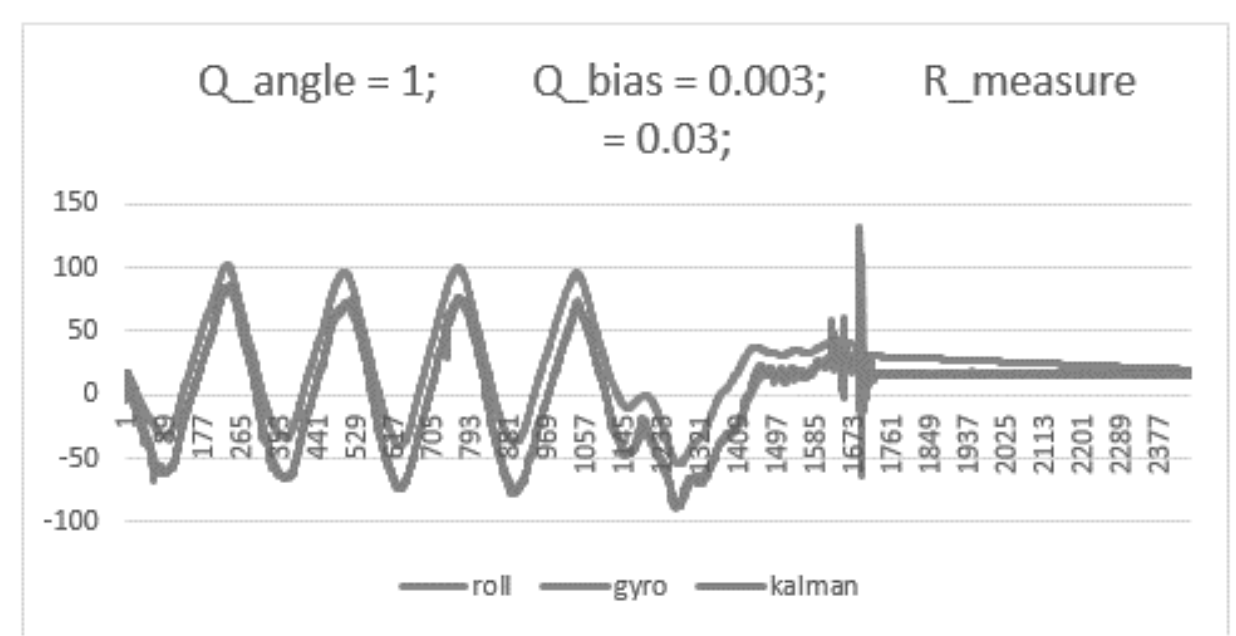

Gambar 18. Tuning Q_w

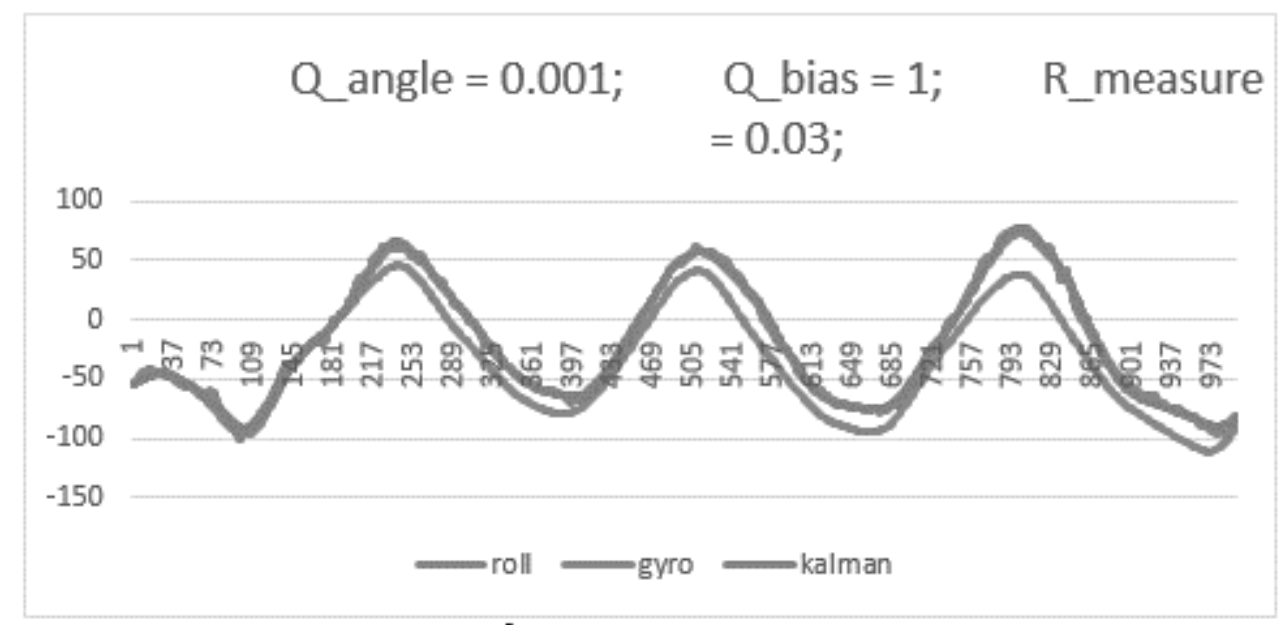

Gambar 19. Tuning Q_w

Jurnal ELKOMIKA Itenas - 157 


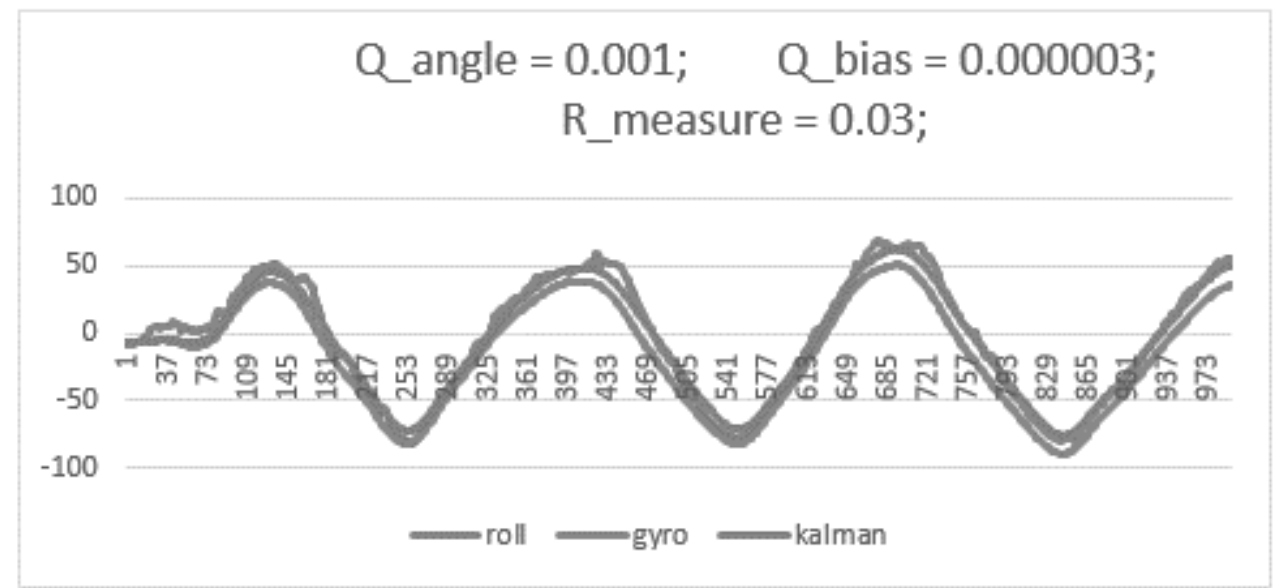

Gambar 20. Tuning Q_w

Pada Gambar 17 sampai 20 menunjukan perbandingan sudut accelerometer dan kalman filter dengan mengubah nilai $Q_{w}$. Perubahan nilai Q_angle dan Q_bias menentukan salah satu nilai lebih dipercaya antara accelerometer dan gyroscope. Jika nilai Q_angel lebih kecil dibandingkan nilai Q_bias maka pembacaan nilai accelerometer lebih dipercaya dibandingkan dengan nilai pembacaan gyroscope, begitu juga sebaliknya.

Setelah melakukan beberapa percobaan untuk mencari nilai $Q_{w}$ dan $R_{v}$ yang optimal. Didapatkan nilai parameter kalman filter yang optimal adalah:

- Q_angle (Q_accelerometer) $\quad=0.001$

- Q_bias (Q_gyroscope) $\quad=0.003$

- R_measure $=0.03$

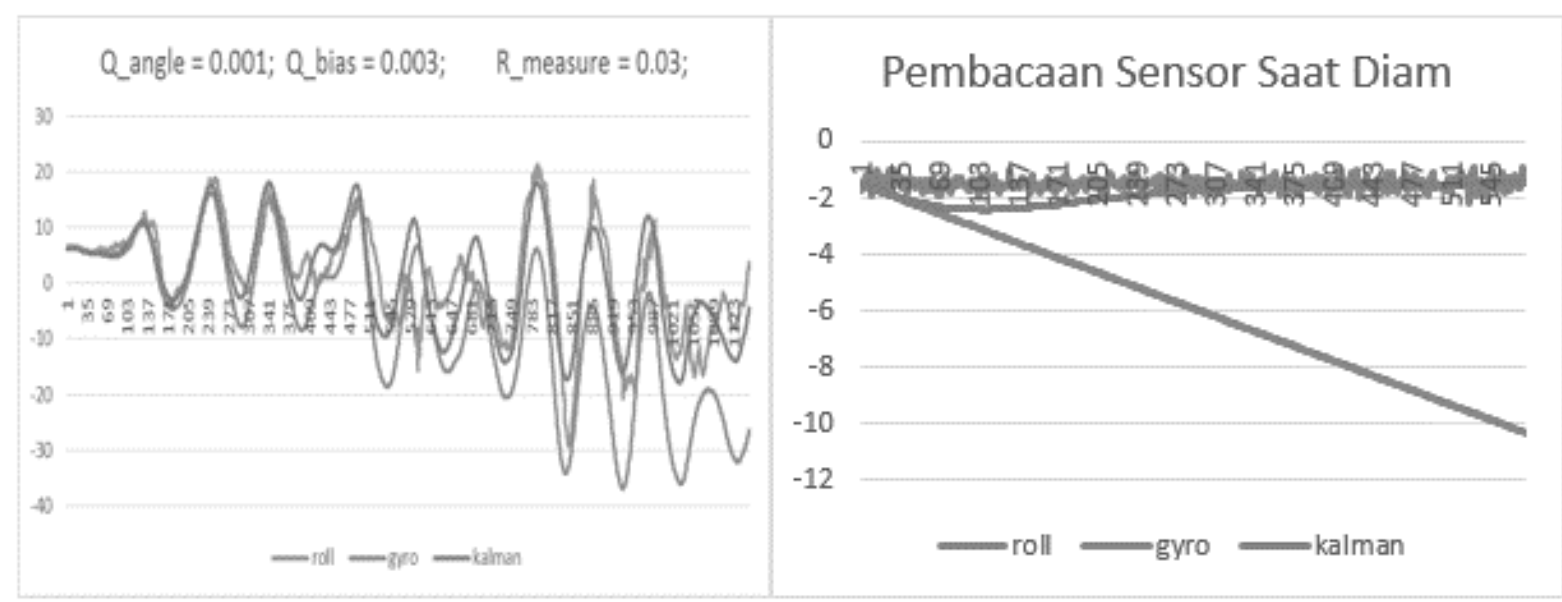

Gambar 21. Tuning yang Optimal 


\subsection{Pengujian Fuzzy Logic}

Tujuan dari Fuzzy Logic adalah kestabilan. Terlihat robot menjaga kestabilannya di sudut $0^{\circ}$. Pada Gambar 22 terlihat bahwa pada awal inisialisasi terdapat sebuah overshoot yang disebabkan initialisasi prediksi sudut kalman, akan tetapi setelah itu overshoot itu hilang.

Parameter Fuzzy ialah : $-20^{\circ},-40,15^{\circ}, 20^{\circ}$.

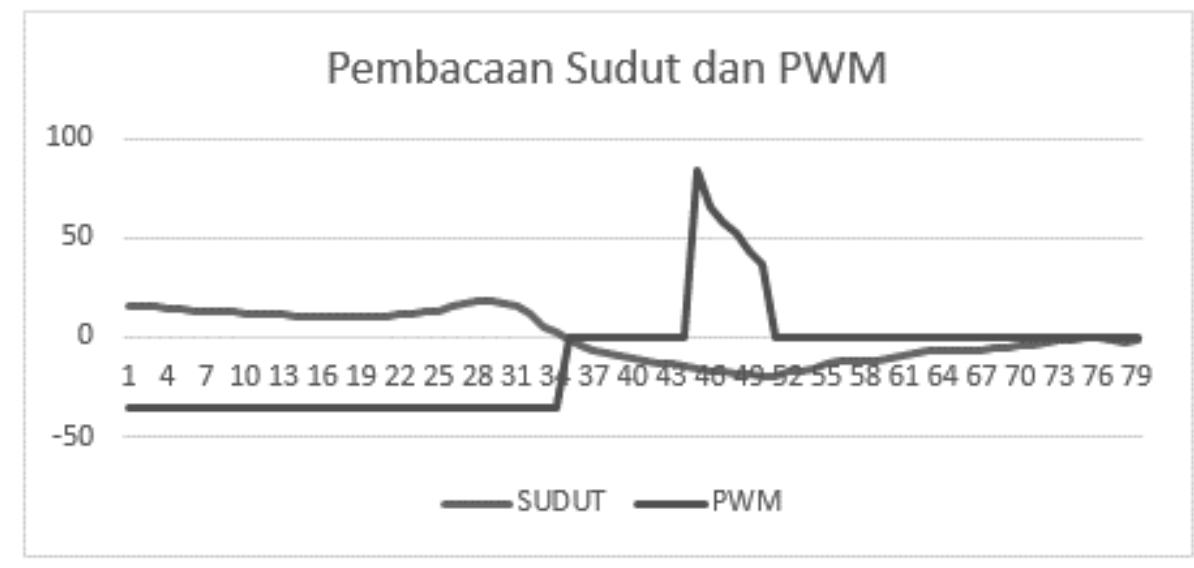

\section{Gambar 22. Pembacaan Sudut dan PWM}

* Jika sudut menunjukkan keluaran negatif yaitu pembacaan posisi robot miring ke belakang maka PWM akan mengeluarkan nilai positif untuk menggerakan motor ke arah depan. Begitu juga sebaliknya.

\section{KESIMPULAN}

Berdasarkan hasil perancangan, implementasi, dan pengujian sistem kendali Fuzzy Logic, dapat disimpulkan bahwa:

1. Dengan menggunakan 2 buah input pada proses fuzzifikasi dan menggunakan 16 rules, robot mampu mencapai kesetimbangannya kembali (steady state) setelah mendapatkan gangguan dari luar. Pengujian robot keseimbangan dengan menggunakan kendali fuzzy logic dapat membuat robot berdiri tegak pada pusat bumi dan robot mampu mencapai tujuan dari penelitian ini ialah mendesain suatu kontrol handal yang dapat membuat robot berdiri tegak.

2. Penggunaan filter pada sensor IMU dengan penggabungan sensor accelerometer dan gyroscope yaitu kalman filter, sangat berguna dan membantu dalam mengurangi noise dan drift pada sensor.

3. Penggabungan sensor accelerometer dan gyroscope menggunakan kalman filter memberikan nilai perhitungan sudut yang lebih baik dibandingkan perhitungan sudut langsung menggunakan accelerometer atau gyroscope. 
4. Pemilihan nilai $Q_{w}$ dan $R_{v}$ pada kalman filter sangat berpengaruh pada nilai keluaran sudut dari sensor IMU. Nilai $Q_{w}$ dan $R_{v}$ yang optimal setelah melakukan beberapa percobaan adalah $Q_{\text {accelerometer }}=0,001 ; Q_{\text {gyroscope }}=0,003$ dan $R_{\text {measurement }}=$ 0,03 .

\section{DAFTAR RUJUKAN}

Wibowo, B.C. dan Iqbal. M. (2013). Implementasi Metode Logika Fuzzy pada Kontrol Keseimbangan Robot Mobil Beroda Dua. Jurnal Universitas Muria. Kudus.

Pamungkas, A.P. Balancing Robot Beroda Dua Menggunakan Metode Fuzzy Logic Berbasis Mikrokontroler Arduino. Fakultas Teknik Elektro, Universitas Dian Nuswantoro.

Priyoprahastyo, L.P. (2015). Design and Implementatio of Collision Avoidance for Automated Guided Vehicle (AGV) Using Ultrasonic Sensors With Fuzzy Logic Methods. Telkom University.

Royyan, M. (2015). Implementation of Kalman Filter and PID Controller for Inverted Pendulum Robot. Telkom University.

Putra, N.W. (2015). Design And Implementation ADCS (Attitude Determination And Control System) For Nano Satellite Using Reaction Wheel. Telkom University

Boskovich, S.M. (1993). A Two Wheeled Robot Control System, California State Polyrechnic University 